\title{
Coronavirus disease-19 and diabetes mellitus: implications for diabetes management in Nigeria
}

\author{
Otovwe Agofure ${ }^{1}$, Anthony Taghogho Eduviere ${ }^{2 *}$, Oghenenioborue Rume Okandeji-Barry ${ }^{3}$
}

\author{
${ }^{1}$ Department of Public and Community Health, Novena University Ogume, Nigeria \\ ${ }^{2}$ Department of Pharmacology and Therapeutics, Delta State University, Abraka, Nigeria \\ ${ }^{3}$ Department of Health and Social Care Management, London School of Management Education, United Kingdom
}

Received: 17 October 2020

Revised: 09 December 2020

Accepted: 14 December 2020

\section{*Correspondence: \\ Dr. Anthony Taghogho Eduviere, \\ E-mail: tonyeduviere@yahoo.com}

Copyright: (c) the author(s), publisher and licensee Medip Academy. This is an open-access article distributed under the terms of the Creative Commons Attribution Non-Commercial License, which permits unrestricted non-commercial use, distribution, and reproduction in any medium, provided the original work is properly cited.

\begin{abstract}
Coronavirus disease-19 is a viral infection that has spread to the entire regions across the globe. Current evidence shows that diabetes mellitus patients are highly susceptible to severe complications, morbidity and mortality due to this infection. The high susceptibility may be as a result of the associated pathophysiology of coronavirus disease-19 and diabetes mellitus co-morbidity in affected individuals. This narrative review was undertaken to highlight the implications of coronavirus disease-19 infection on diabetes mellitus patients in developing countries with a focus on Nigeria which has a weak health care system and poor clinical patients' characteristics. A critical literature search was carried out on coronavirus disease-19 and diabetes mellitus. Relevant items were assembled to form the current review on coronavirus disease-19 infections and its implications on diabetes mellitus management in developing countries. The review highlighted the significance of proper glycaemic control as coronavirus disease-19 increases the susceptibility of diabetes mellitus patients to morbidity and mortality which could be overwhelming as the incidence of the infection increases across developing countries like Nigeria.
\end{abstract}

Keywords: Coronavirus disease-19, Diabetes Mellitus, Developing Countries, Nigeria

\section{INTRODUCTION}

Coronavirus 2019 (COVID-19) is an infectious disease that is caused by the newly discovered coronavirus, currently called severe acute respiratory syndrome coronavirus 2 (SARS-CoV-2). ${ }^{1,2}$ The world is currently experiencing the COVID-19 pandemic, which began in the metropolitan city of Wuhan, China in December 2019 and with infections reaching out to about 5 million people globally. ${ }^{1,3}$ Based on available data from the WHO, the number of confirmed cases is now in millions and death toll due to COVID-19 worldwide has risen to hundreds of thousands. ${ }^{1}$
People are affected by COVID-19 in diverse ways, and most infected people will develop mild to moderate symptoms. Common symptoms include fever, tiredness, and dry cough while some people may experience aches and pains, nasal congestion, running nose, sore throat, and diarrhoea, among others. On average, it takes 5 - 6 days from when someone is infected with the virus for symptoms to show; nonetheless it can take up to 14 days. ${ }^{1}$ However, while COVID-19 patients are expected to recover within days of being ill, older patients and others with underlying medical conditions like diabetes and cardiovascular diseases are more likely to develop severe illness. ${ }^{4-6}$ 
Epidemiological evidence from other regions of the world severely affected by the SARS-CoV-2 infection showed that the risk of fatal outcome due to COVID-19 is approximately $50 \%$ higher in patients who suffer diabetes as co-morbidity as compared to non-diabetes. ${ }^{7,8}$ Moreover, several hypotheses may explain the increased occurrence and severity of COVID-19 in patients with diabetes. It has been observed that persons with any form of diabetes are at higher risk of bacterial, fungal, and viral infections because of deficiencies in innate immunity which compromise phagocytosis, neutrophil chemotaxis, and cell-mediated immunity. Nevertheless, the high occurrence of COVID-19 severe cases and fatality in older patients might reflect the higher prevalence of diabetes in older people. Likewise, diabetes in older age is associated with cardiovascular disease and may explain the association with fatal outcomes of COVID-19. ${ }^{7}$

\section{METHODS}

Articles adopted for the review covered a period of 20102020. Google search engine was used to access Google Scholar, PubMed, African Journal Online and Science Direct related materials on COVID-19 and Diabetes Care in developing countries. In all 40 articles were accessed. The study types of the adopted articles were randomized controlled studies, cohort studies, clinical studies, case studies, case reports and cross-sectional studies. Search themes were developed from the study objectives to serve as guides to extract relevant information on COVID-19 and diabetes care in developing countries with a special focus on Nigeria. Information searched for were diabetes care in developing countries, diabetes care in Africa, diabetes care in Nigeria. The information collected was subjected to thematic analysis based on the objectives of the study. The findings were presented as a narrative in thematic prose with figures.

\section{DISCUSSION}

\section{Associated pathophysiology of diabetes and COVID-19}

Diabetes mellitus (DM), a disease characterised by hyperglycaemia due to insulin deficiency is one of the risk factors of increased COVID-19 morbidity and mortality. The associated pathophysiology is that DM patients have impaired immune-response to infection with a cytokine profile and to changes in immune responses, including T-cell and macrophage activation. ${ }^{9}$ Coronaviruses primarily infect vascular endothelial cells as well as epithelial cells of the airway and alveolar, and macrophages. Also, their viral particles are detectable in monocytes and lymphocytes. ${ }^{10}$ The SARS-CoV-2 employs the same entry receptor, which is angiotensinconverting enzyme 2 (ACE2), like SARS-CoV-1, which means that the same set of cells is possibly being targeted and infected. ${ }^{11,12}$ The ACE2 plays a protective role against inflammatory processes. The virus gains access into the host cell and attaches itself to the ACE2 via the spike protein on its surface. Upon entry of the virus into the lungs, massive epithelial and endothelial cell apoptosis and vascular leakage may cause the initial onset of rapid viral replication.

Consequently, prompting increased secretion and the release of exuberant pro-inflammatory cytokines and chemokines in infected persons, suggesting a possible "cytokine storm". This may be associated with a probable secondary development of a hemophagocytic lymphohistiocytosis which is noticed in COVID-19 severity, requiring prompt admission at intensive care units in hospitals., ${ }^{4-13}$ Besides, the viral infection may also cause pyroptosis in macrophages and lymphocytes, due to its ability to attenuate ACE2 expression and prompts cellular injury, hyper inflammation, as well as a respiratory failure., ${ }^{4,16}$ Moreover, loss of pulmonary ACE2 function has also been suggested to be linked with acute lung injury; the reduction in ACE2 function can cause dysfunction of the renin-angiotensin system (RAS) and enhance inflammation and vascular permeability. ${ }^{17-21}$

Chronic hyperglycaemia, as seen in DM patients, causes downregulation in the expression of ACE2, which makes the cells of the host to be much more vulnerable to inflammatory and organ failure caused by the disease. Moreover, the pancreatic $\beta$ cells, which also serve as a reservoir of ACE2, and upon downregulation can lead to a direct effect on $\beta$ cell functions. ${ }^{7}$ Furthermore, several features of the immune system as a major response to viral infection, including possible bacterial secondary infection in the lungs are impaired by poor glycaemic control. ${ }^{22}$ Poor glycaemic control is also a risk factor for serious infections and adverse outcomes, including diabetic complications. However, good glycaemic control reduces the risk of infections, including bacterial pneumonia which is a common complication of COVID19. DM patients with poor glycaemic control have a higher rate of developing serious complications from COVID-19 than patients with better control and people without DM. ${ }^{22}$ This is because viral infections cause inflammation in DM patients which could lead to more severe complications. Furthermore, viral infections increase the risk of developing diabetic ketoacidosis among DM patients. This becomes very challenging for DM patients to manage their fluid intake and electrolyte levels which is pertinent in managing sepsis and septic shock. $^{23}$

Also, it has been observed that a host of viruses including coronaviruses are capable of activating and compromising the coagulation system, which could lead to the development of the thromboembolic disorder in severely affected patients. ${ }^{24,25}$ There exists a physiological haemostatic balance between coagulation

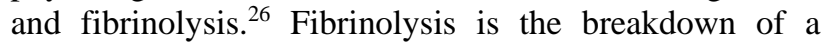
covalently cross-linked fibrin clot by plasmin, a proteolytic enzyme thus resulting in the production of fibrin (D-dimer) which serves as an index of coagulatory activity. ${ }^{26}$ Elevated D-dimer levels have been found in COVID-19 patients recently and in DM patients, 
previously, which underpins a potential risk of development of the thrombotic disorder in patients with both conditions. ${ }^{27-30}$ Furthermore, increasing evidence are pointing to the occurrence of venous thromboembolism and pulmonary embolism in COVID-19 patients with comorbidities such as DM. ${ }^{27,31}$ In 2003, during SARS-CoV1 pandemic, it was stated that the virus caused injury to vascular endothelial pulmonary vessels which resulted in pulmonary infraction such as; disseminated intravascular coagulation, venous thromboembolism and pulmonary embolism in severely affected persons. ${ }^{32,33}$ Since, SARSCoV-1 and SARS-CoV-2, are roughly $82 \%$ alike, it suffices to hypothesise that SARS-CoV-2 may produce similar thrombotic distress as SARS-CoV-1, which is presently observed in patients with a severe case of COVID-19. ${ }^{34}$ It is currently unclear whether the coagulation cascade is activated directly by the virus or it is due to systemic inflammation. However, there is the observation that depletion of natural cellular antioxidants by hyperglycaemia as seen in DM may lead to enhanced activation of the nuclear redox-sensitive transcription factor, which in turn up-regulates events at the gene level, including pro-coagulant tissue factor. ${ }^{35}$ The stated cascades of the event may also contribute to the severe complications, morbidity, and mortality seen in COVID19 patients with DM as co-morbidity. Nonetheless, the respiratory failure noticed in severe COVID-19 cases may probably not be associated with acute respiratory distress syndrome only, but might include the perturbation of thrombotic processes due to the presence of the virus in the body system including DM as co-morbidity. ${ }^{27}$

\section{Implications of COVID-19 management among DM patients}

Current reports in literature underscore the evidence that persons with DM are at higher risk of complications, including death, due to COVID-19. ${ }^{5-7,36}$ DM patients with poor glycaemic control are at increased risk of experiencing severe complications when infected with COVID-19. Thus, glycaemic control is pertinent to the survival of DM patients in this current pandemic. The implications would be discussed at two levels. Firstly, at the patient level and secondly at the health care level.

\section{Patient-level}

Reports reveal that poor glycaemic control is a norm among DM patients in developing countries like Nigeria. ${ }^{37-39}$ This is because there is poor awareness of DM among the general population including knowledge of the critical elements of DM (definition, causes, signs, and symptoms, risk factors, management, and prevention) among DM patients. ${ }^{40-43}$ Furthermore, DM patients in low resource settings like Nigeria are having problems with adherence to both dietary, physical activity, and medication treatment. ${ }^{44-47}$ Also, socio-cultural and religious beliefs are characteristics of DM patients reported as mitigating the achievement of optimum glycaemic control. ${ }^{48}$ This has made DM management and controls difficult, resulting in complications among DM patients. ${ }^{49-52}$ Most DM patients are already struggling with DM related complications, and combining it with COVID-19 would result in increased morbidity and mortality among DM patients. Thus, apart from the problem of maintaining and regulating blood glucose levels; DM patients would have to contend with complications of COVID-19, which in no doubt would be devastating to their health and wellbeing.

Furthermore, due to the policy of total or partial lockdowns and other restrictive measures instituted by the government to ensure the spread of COVID-19 is controlled, DM outpatients and other patients with terminal diseases may be unconsciously denied free access to procure medication and to healthcare facilities. This could make some DM patients cancel their routine check-ups at diabetes clinics, thus putting them at risk of DM complications and further predisposing them to COVID-19 infections via community transmission. As a result, COVID-19 would present a health challenge for DM patients as the pandemic is on the increase in developing countries like Nigeria.

\section{Health care level}

DM management and control in Nigeria, health care system, is substandard, especially at the primary and secondary levels of healthcare. The tertiary level of care is the only equipped level of care that can cater for DM patients effectively. Most facilities have little presence of diabetologists and endocrinologists as well as poor government funding and support. ${ }^{43,53}$ The consistent increase of out-of-pocket expenditure among DM patients with little or no insurance package is part of the effect of insufficient funding in the health sector. Besides, poor referral system among the three tiers of healthcare (primary, secondary and tertiary); and absence of interdisciplinary diabetes care team and other specialised professionals make adequate monitoring and follow-up of DM patients with severe complications difficult. ${ }^{43,54-56}$ More so, lack of tools and basic infrastructure is reported to be responsible for much of the failure in early Identification and adequate management of DM in low resource settings like Nigeria. ${ }^{48}$ Combining the challenges faced by DM patients with the current prevalence of the COVID-19 pandemic would serve as a health crisis for DM patients as the available report is already showing that severe morbidity and mortality were reported more among DM patients. Also included are patients with other co-morbid conditions such as cardiovascular diseases, respiratory conditions with COVID-19 than COVID-19 patients without these conditions. ${ }^{4-6}$

\section{CONCLUSION}

As the COVID-19 pandemic is currently spreading across developing countries including Nigeria adequate facilities and management practices must be put in place across isolation centres to protect DM patients with COVID-19 
to minimise the rate of morbidity and mortality among cases associated with both conditions.

\section{Recommendations}

Based on the aforementioned obvious reasons and factors that potentially predispose individuals with DM to increased risk of COVID-19 severity and possibly death upon infection; a more robust response plan for monitoring and follow-up of DM patients should be instituted at the health care level to help optimise glycaemic control among DM patients. Also, more tools and basic infrastructure should be put in place for early identification and adequate management of DM. There should be more concerted effort to sensitise the general public, most especially rural communities via health awareness programmes which will underscore the essentials of proper health-seeking behaviours and adherence to treatment modalities of DM. Furthermore, DM patients in developing nations should be made to understand the potential complications, morbidity and mortality which may arise in the advent of COVID-19 infection as well as the need to take personal responsibility and strictly adhere to the general precautionary measures suggested by the WHO and the respective national centre for disease control (CDC). This includes; constant hand washing, the use of hand sanitiser, wearing a nose mask while living the home, maintenance of physical distance, among others. Also, as a measure to circumvent the current restrictions due to lockdown in the country, the use of telemedicine could be a consideration as one of the management options for DM patients.

\section{Funding: No funding sources Conflict of interest: None declared \\ Ethical approval: Not required}

\section{REFERENCES}

1. World Health Organisation. Coronavirus disease (COVID-19) Situation Report- 122. Available at: https://reliefweb.int/report/world/coronavirusdisease-2019-covid-19-situation-report-122-21-may2020. Accessed on 20 October 2020.

2. Centre for Disease Control. Novel Coronavirus, Wuhan, China. CDC 2019. Available at https://www.cdc.gov/coronavirus/2019ncov/about/index.html.January 26, 2020; Accessed on 27 January 2020.

3. Ren LL, Wang YM, Wu ZQ. Identification of a novel coronavirus causing severe pneumonia in human: a descriptive study. Chin Med J. 2020.

4. Yang X, Yu Y, Xu J, Shu H, Liu H, Wu Y, et al. Clinical course and outcomes of critically ill patients with SARS-CoV-2 pneumonia in Wuhan, China: a single-centered, retrospective, observational study. Lancet Respirat Med. 2020.
5. Guan WJ, Ni ZY, Hu Y. Clinical characteristics of coronavirus disease 2019 in China. N Engl J Med 2020.

6. Zhang JJ, Dong X. Clinical characteristics of 140 patients infected with SARS-CoV-2 in Wuhan, China. Allergy 2020.

7. Bornstein SR, Rubino F, Khunti K. Practical recommendations for the management of diabetes in patients with COVID-19. Lancet Diabet Endocrinol. 2020.

8. Remuzzi A, Remuzzi G. COVID-19 and Italy: what next? Lancet 2020;395:1225-8.

9. Ferlita S, Yegiazaryan A, Noori N, Lal G, Nguyen T, To K, et al. Type 2 diabetes mellitus and altered immune system leading to susceptibility to pathogens, especially mycobacterium tuberculosis. J Clinic Medic. 2019;8(12):2219.

10. Gu J, Gong E, Zhang B, Zheng J, Gao Z, Zhong Y, et al. Multiple organ infection and the pathogenesis of SARS. J Experiment Medic. 2005;202(3):415-24.

11. Wan Y, Shang J, Graham R, Baric RS, Li F. Information: read \& look at all below.

12. Zhou P, Yang X. A pneumonia outbreak associated with a new coronavirus of probable bat origin. Nature, 2020.

13. Chen Z, McCrosky S. guo W. Li H and gerton JL: A genetic screen to discover pathways affecting cohesin function in Schizosaccharomyces pombe identifies chromatin effectors. g3 (Bethesda). 2012;2:1161-8.

14. Mehta P, Mcauley D, Brown M. HLH Across Speciality Collaboration, UK. Correspondence COVID-19: consider cytokine storm syndromes and immunosuppression. Lancet. 2020;395:1033-4.

15. Yang X, Yu Y, Xu J, Shu H, Liu H, Wu Y, et al. Clinical course and outcomes of critically ill patients with SARS-CoV-2 pneumonia in Wuhan, China: a single-centered, retrospective, observational study. Lancet Respirat Medic. 2020.

16. Hoffmann M, Kleine-Weber H, Schroeder S. SARSCoV-2 cell entry depends on ACE2 and TMPRSS2 and is blocked by a clinically proven protease inhibitor. Cell. 2020

17. Imai Y, Kuba K, Rao S, Huan Y, Guo F, Guan B, et al. Angiotensin-converting enzyme 2 protects from severe acute lung failure. Nature. 2005;436(7047):112-6.

18. Imai Y, Kuba K, Penninger JM. The discovery of angiotensin converting enzyme-2 and its role in acute lung injury in mice. Exp Physiol. 2008;93:543-8

19. Kuba K, Imai Y, Rao S, Gao H, Guo F, Guan B, et al. A crucial role of angiotensin converting enzyme 2 (ACE2) in SARS coronavirus-induced lung injury. Nature Medic. 2005;11(8):875-9.

20. Kuba K, Imai Y, Penninger JM. Angiotensinconverting enzyme 2 in lung diseases. Curr Opin Pharmacol. 2006;6:271-6.

21. Yajing F, Yuanxiong C, Yuntao W. Understanding SARS-CoV-2-Mediated Inflammatory Responses: 
From Mechanisms to Potential Therapeutic Tools. Virologica Sinica. 2020.

22. Critchley JA, Carey IM, Harris T. Glycemic control and risk of infections among people with type 1 or type 2 diabetes in a large primary care cohort study. Diabetes Care, 2018;41:2127-33

23. Li B, Yang J, Zhao F. Prevalence and impact of cardiovascular, metabolic diseases on COVID-19 in China. Clin Res Cardiol. 2020.

24. Antoniak S, Mackman N. Multiple roles of the coagulation protease cascade during virus infection. Blood. 2014;123:2605-13.

25. Antoniak $\mathrm{S}$. The coagulation system in host defence. Res Pract Thromb Haemost. 2018;2:549-57.

26. Miller JL. Blood coagulation and fibrinolysis. In: Henry JB, editor. Clinical Diagnosis and Management by Lab Methods. 17th ed. Philadelphia: WB Saunders, 2001;767-72.

27. Oudkerk M, Büller HR, Kuijpers D, et al. Diagnosis, Prevention, and Treatment of Thromboembolic Complications in COVID-19: Report of the National Institute for Public Health of the Netherlands, Radiology. 2020.

28. Nwose E, Jelinek H, Richards R. D-dimer levels in diabetes. Proceedings of the Australian Health and Medical Research Congress. 2004;232.

29. Nwose E, Richards R, Jelinek H. D-dimer identifies stages in the progression of diabetes mellitus from family history of diabetes to cardiovascular complications. Pathology. 2007; 39(2):252-7.

30. Heit JA, Leibson CL, Ashrani AA. Is Diabetes Mellitus an Independent Risk Factor for Venous Thromboembolism? A Population-Based CaseControl Study. Arterioscler Thromb Vasc Biol. 2009;29(9):1399-405.

31. Poissy J, Goutay J, Caplan M. Pulmonary Embolism in COVID-19 Patients: Awareness of an Increased Prevalence. 2020.

32. Wong RS, Wu A, To KF, et al. Haematological manifestations in patients with severe acute respiratory syndrome: retrospective analysis. Bio Med J. 2003;326:1358-62.

33. Hwang DM, Chamberlain DW, Poutanen SM, et al. Pulmonary pathology of severe acute respiratory syndrome in Toronto. Mod Pathol. 2005;18:1-10.

34. Zhang L, Lin D, Sun X. Crystal structure of SARSCoV-2 main protease provides a basis for the design of improved $\alpha$-ketoamide inhibitors. Science. 2020;368(6489):409-12.

35. Ziegler D, Sohr CGH, Nourooz-Zadeh J. Oxidative stress and antioxidant defence in relation to the severity of diabetic polyneuropathy and cardiovascular autonomic neuropathy. Diabetes Care. 2004;27:2178-83.

36. Hill MA, Mantzoros C, Sowers JR. Commentary: COVID-19 in patients with diabetes. Metab Clin Exp 2020;107:154217.

37. Chukwuani U, Yovwin DG, Digban KA. Determinants of glycemic control among persons with type 2 diabetes mellitus in Niger Delta. Sahel Med J. 2016;19(4):190-5.

38. Unadike BC, Eregie A, Ohwovoriole AE. Glycaemic control amongst persons with diabetes mellitus in Benin City. Nig Med J 2010;51(4):164-6.

39. Olayemi IA, Osazuwa F. Prevalence of poor glycemic control among Nigerian female diabetics. Niger J Exp Clin Biosci. 2014;2:67-8.

40. Ndibuagu EO, Arinze-Onyia SU, Chime OH. Knowledge and attitude on diabetes mellitus among residents of a rural community in Enugu State, Southeast, Nigeria. Int Res J Medical Sci. 2016;4:17.

41. Uchenna D, Ambakederemo TE, Jesuorobo DE. Awareness of heart disease prevention among patients attending a specialist clinic in Southern Nigeria. Int J Prevent Treatm. 2012;1:40-3.

42. Odili VU, Isiboge PD, Eregie A. Patients' Knowledge of diabetes mellitus in a Nigerian city. Trop J Pham Res. 2011;10:637-42.

43. Agofure O, Oyewole OE, Igumbor EO. Diabetes care in delta state of Nigeria: An expository review. Diabetes Updates. 2018;1(1):1-8.

44. Oyewole EO, Agofure O. Patterns of adherence to management among patients with type 2 diabetes mellitus in the South-South Region of Nigeria. J Soc Heal Diabet. 2015;3:115-9.

45. Fadare J, Olamoyegun M, Gbadegesin BA. Medication adherence and direct treatment cost among diabetes patients attending a tertiary healthcare facility in Ogbomosho, Nigeria. Malawi Med J. 2015;27(2):65-70.

46. Pascal IG, Ofoedu JN, Uchenna NP. Blood Glucose Control and Medication Adherence Among Adult Type 2 Diabetic Nigerians Attending A Primary Care Clinic in Under-resourced Environment of Eastern Nigeria. N Am J Med Sci. 2012;4(7):310-5.

47. Adisa R, Fakeye TO. Effect of number and type of antidiabetes medications on adherence and glycemia of ambulatory type 2 diabetes patients in southwestern Nigeria. Pharm Pract (Granada). 2013; 11(3):156-65.

48. Nwankwo CU, Ezenwaka CE, Onuoha PC, Agbakoba NR. Implementing diabetes selfmanagement education (DSME) in a Nigerian population: perceptions of practice nurses and dieticians. Arch Physiol Biochem. 2015;121:123-7.

49. Nwose EU, Oguoma VM. Metabolic syndrome and prediabetes in Ndokwa community of Nigeria: preliminary study. N Am J Med Sci. 2015;7:53-8.

50. Aguocha BU, Ukpabi JO, Onyeonoro UU. Pattern of diabetic mortality in a tertiary health facility in south-eastern Nigeria. Afr J Diab Med. 2013;21:146.

51. Chijioke A, Adamu AN, Makusidi AM. Mortality patterns among type 2 diabetes mellitus patients in Ilorin, Nigeria. J Endocrinol Metabol Diabet South Afr. 2010;15:79-82.

52. Unadike BC, Essien I, Akpan NA, Peters EJ, Essien OE. Profile and outcome of diabetic admissions at 
the University of Uyo Teaching Hospital, Uyo. Int J Medic Medical Sci. 2013;5(6):286-9.

53. Fasanmade OA, Dagogo-Jack S. Diabetes care in Nigeria. Ann Glob Health. 2015;81:821-9.

54. Awosusi A, Folaranmi T, Yates R. Nigeria's new government and public financing for universal health coverage. Lancet Global Heal. 2015;3:514-5.

55. Akande TM. Referral system in Nigeria: Study of a tertiary health facility. Ann Afri Med. 2004;3:130-3.

56. Otovwe A, Baba A. Knowledge of referral and feedback system among health workers in billiri local government area of Gombe State, Nigeria. Europ J Pharmaceut Medic Res. 2016;3:111-55.

Cite this article as: Agofure O, Eduviere AT, Okandeji-Barry OR. Coronavirus disease-19 and diabetes mellitus: implications for diabetes management in Nigeria. Int J Community Med Public Health 2021;8:969-74. 